\title{
Suicide Ideation, School Absenteeism and Physical Violence among Secondary School Students in Kampala, Uganda
}

\author{
Samuel Sendagala ${ }^{1}$, John M. Ssenkusu ${ }^{2}$, George W. Lubwama ${ }^{3}$, Danstan Bagenda ${ }^{4}$, \\ Michael Muyonga ${ }^{5}$, Wolfgang Hladik ${ }^{6}$ \\ ${ }^{1}$ Division of Global HIV/AIDS and TB, Centers for Disease Control and Prevention, Entebbe, Uganda \\ ${ }^{6}$ Division of Global HIV/AIDS and TB, Centers for Disease Control and Prevention, Atlanta, Georgia, USA \\ ${ }^{3,4}$ School of Public Health, Makerere University, Kampala, Uganda \\ ${ }^{5}$ Ministry of Health, Kampala, Uganda \\ ${ }^{2}$ School of Public Health, Division of Biostatistics, University of Minnesota, Minneapolis, Minnesota, USA \\ ${ }^{4}$ Department of Anesthesiology, University of Nebraska Medical Center, Omaha, Nebraska
}

\section{Article Info}

Article history:

Received Jul 24, 2018

Revised Nov 8, 2018

Accepted Nov X, 2018

\section{Keyword:}

Alcohol use

Bullying

Illicit drug use

Physical violence

School absenteeism

Secondary school students

Smoking

Suicidal ideation

\begin{abstract}
School youth in many African countries face a range of non-infectious health risks, in addition to the infectious disease burden typical in resource-limited settings. We examined self-reported health behaviors associated with suicide ideation, school absenteeism and physical violence among secondary school students in Kampala, Uganda. We conducted a cross-sectional three-stage cluster-based survey among students aged $>=15$ years, and/or enrolled in forms 3-6 (grades 9-12) in 54 secondary schools in Kampala. Interview data were collected with a standardised electronic questionnaire through computer-assisted self-interviewing and results were weighted for sample design and non-response. Pearson's chi-square and logistic regression methods were used for bivariate and multivariate analysis respectively. Bullying among female respondents was positively associated with suicide ideation $(\mathrm{aOR}=1.73)$. In multivariate analysis, suicidal ideation was positively associated with a lifetime exposure to illicit drug use (aOR=1.76), serious injury $(\mathrm{aOR}=1.67)$ or school absenteeism $(\mathrm{aOR}=1.46)$. School absenteeism was positively associated with serious injury $(\mathrm{aOR}=1.59)$, history of alcohol consumption $(\mathrm{aOR}=1.55)$, bullying $(\mathrm{aOR}=1.52)$ and suicide ideation $(\mathrm{aOR}=1.45)$. Serious injury $(\mathrm{aOR}=2.89)$, a life-time history of illicit drug use $(\mathrm{aOR}=2.65)$, recent history of having been bullied $(\mathrm{aOR}=2.38)$, physical activity $(\mathrm{aOR}=2.12)$, suicide ideation $(\mathrm{aOR}=1.58)$, school absenteeism $(\mathrm{aOR}=1.57)$ were associated with having been engaged in physical violence. Bullying, serious injury and illicit drug use were associated with suicidal ideation, school absenteeism and physical violence. Concerted efforts should be considered by education authorities, parents and the community to tackle these risky behaviors.
\end{abstract}

Copyright @ 2018 Institute of Advanced Engineering and Science. All rights reserved.

\section{Corresponding Author:}

Samuel Sendagala,

Division of Global HIV/AIDS and TB,

Centers for Disease Control and Prevention,

Entebbe, Uganda.

Email address: hlw6@cdc.gov

\section{INTRODUCTION}

In 2010, the global population of young people aged between 15 and 24 years was estimated to be more than 1.2 billion, representing $17.6 \%$ of the global population [1]. Sub-Saharan Africa is host to $14.2 \%$ of the 15- to 24-year-old population worldwide [1]. 20.6\% of the Uganda population is between 15 and 24 years[2]. The size of this population category highlights its importance and the need to focus on their health 
concerns globally and Uganda specifically. Although lifestyle, and the adverse health behaviors which have harmful effects on health or otherwise predispose individuals to disease that young people adopt might not affect their health during this period, they can have substantial effects later in life [3-5]. For example, nearly two thirds of premature deaths and one third of the total disease burden in adults are associated with conditions or behaviors that began in youth, including tobacco use, lack of physical activity, unprotected sex, or exposure to violence[6, 7].

In 2012, infectious diseases were the leading cause of death among the 15-29 and 30-59 year-olds in sub-Saharan Africa accounting for $42.1 \%$ and $51.9 \%$ respectively. This was followed by injuries $(36.4 \%)$ among the 15-29 year-olds and non-infectious diseases(34.2\%) among the 30-59 year olds. [8]. Among the 15-29 year-olds, of all deaths due to injuries, $61.9 \%$ were unintentional and $38.1 \%$ were intentional injuries. [8]. In developing countries, unintentional injuries are a leading cause of death and disability in adolescents and injury rates are highest among adolescents, compared to other age groups [9-11]. At least $20 \%$ of young people will experience mental health problems, including depression, mood disturbances, substance abuse, suicidal behaviors or eating disorders[12]. Overweight and obesity is increasing among young people in both low and high-income countries [13-15].

Adverse health behaviors such as bullying, violence, tobacco smoking, alcohol, eating unhealthy foods, suicidal ideation, and illicit drug use have been shown to be prevalent among adolescents in secondary schools [16-20]. Certain adverse health behaviors seem to differ by gender; for example, Siziya et al. found the prevalence of cigarette smoking in male adolescent students in Kilimanjaro, Tanzania, to be twice as high as that in females [21, 22]. Many negative consequences accompany some of these adverse health behaviors, including criminal prosecution, school failure and dropout, substance dependence, unintended pregnancy, and sexually transmitted infections (STI), notably human immunodeficiency virus (HIV )[23-25].

Studies have shown associations between adverse health behaviors including alcohol and illicit substance use and an increased risk of violent behavior [26]. Farhat and colleagues, in their study of United States youth found overweight and obesity to be associated with adverse health behaviors like cigarette smoking, alcohol and substance use [27].

The Global School-based Student Health Surveys (GSHS) involving secondary school children aged 13-15 years was conducted in 19 low and middle-income countries between 2003 and 2006. Data from the survey showed that Ugandan students frequently reported alcohol consumption (12.8\%), illicit drug use (8.5\%), being bullied in the preceding 30 days (45.5\%), suicide ideation in the preceding 12 months (18.8\%, girls: $22.8 \%$, boys: $14.5 \%$ ) and tobacco use in the last 30 days (4.3\%) [28].

Few recent studies have been conducted in sub-Saharan Africa among adolescents in secondary schools that describe the occurrence and relationship between adverse health behaviors; of those studies published they only focus on few key adverse health behaviors such tobacco smoking [22, 29, 30], bullying[25], physical fighting[18] and suicidal ideation[20]. Whereas such information is important for youth health policy formulation and programming efforts, no data that adequately describes Ugandan secondary school students' adverse health behavior is available. We report here on the findings of a 2010 survey among secondary school students in Kampala, Uganda, that examined self-reported suicide ideation, school absenteeism and engagement in physical fighting.

\section{RESEARCH METHOD}

\subsection{Survey setting and population}

A cross-sectional survey was conducted among secondary school students in Kampala, Uganda. Data was collected between June and October 2010. The eligibility criteria for survey participation included age 15 years or older and/or enrolled in forms 3-6 (grades 9-12) in selected secondary schools, and fluency in English language.

\subsection{Sampling design}

A three-stage cluster sampling design was used to draw a representative sample of students in forms 3-6 (grades 9-12) in both public and private secondary schools in Kampala. Figure 1 illustrates the sampling process. Secondary schools in Kampala have forms from 1 through 6 (grades 7-12). Each form may consist of one or more "streams" depending on the number of students per form. In the first stage, the sampling frame consisted of all Kampala secondary schools $(\mathrm{N}=275)$. From this list 78 schools were randomly selected. In each selected school, one stream per form (i.e., four streams per school) was randomly selected. For each selected stream, a listing of all students was compiled (alphabetically) and up to 31 students were systematically selected, by choosing every nth student, and offered survey participation. For selected students who refused to participate or were absent, or were ineligible, investigators selected the next student on the list as a replacement. If that "replacement student" was not available for survey participation either, the student 
on the list before the original unavailable student was selected. If that second replacement student was also not available, no replacement was chosen for that student.

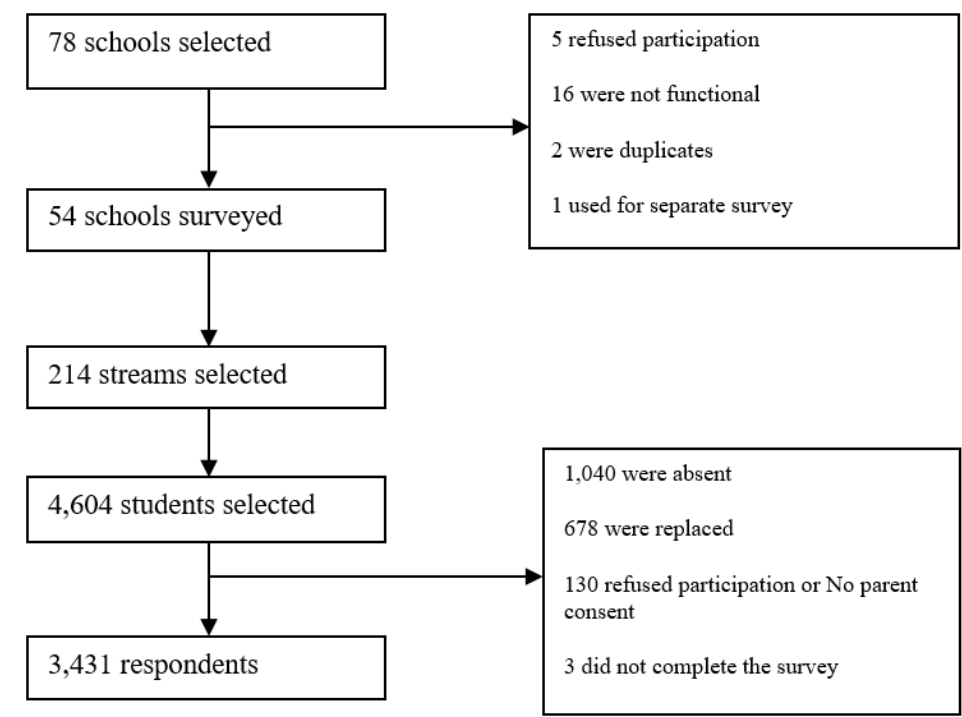

Figure 1. Study sampling process

\subsection{Data measures}

Data collection took place at the school premises, in vacant rooms assigned by the school principal, such as the library or laboratory. Selected students were asked to come to the interview room in batches of approximately half a dozen at a time. Height and weight were measured using stadiometers and scales. A standardized electronic questionnaire, in English, using computer-assisted self-interviewing technology without audio (CASI, Questionnaire Design Studio version 2.5, Nova Research, Bethesda, Maryland, USA) was used to collect interview data. Students who had trouble using handheld computers (HTC Advantage, HTC Corporation, New Taipei, Taiwan) were offered computer assisted personal interviews (CAPIs). The questionnaire had 193 closed-ended questions on demographics, schooling, physical activity (engagement in sports, playing with friends or walking to school), hygiene, diet, mental health, alcohol, drugs, smoking, violence, bullying and injuries, HIV/AIDS knowledge, sexual experience, sexual networks, HIV testing, HIV perceptions, and sexually transmitted diseases.

For this paper, the independent variables were: Weight control assessed by the question "In the past 30 days, did you vomit or take laxatives to lose weight or to keep from gaining weight?"; Physical activity assessed by "During the past 7 days, on how many days were you physically active for a total of at least 1 hour per day"; Ever alcohol use assessed by "Did you ever drink alcohol"; Ever smoked assessed by "Have you ever smoked tobacco?"; Bullying assessed by "During the past 30 days, on how many days were you bullied?"; Serious injury assessed by “ During the past 12 months, how many times were you seriously injured?" and Ever used illicit drugs assessed by asking the respondent how many times in their lifetime have they used drugs such as marijuana or banghi, khati, etc.

The dependent variables were: Suicide ideation measured through the question "Did you ever seriously consider attempting suicide in the past 12 months?"; school absenteeism was defined as having missed any class or school without permission in the last 30 days; and engagement in physical violence was examined by asking the respondent whether s/he was engaged in any "physical fight as a perpetrator or victim" in the preceding 12 months.

\subsection{Data management and analysis}

SAS (SAS Institute, Cary, North Carolina, USA) was used for data management, including the categorization of continuous data, and the creation of new, secondary variables. Data analysis was conducted in STATA version 10.0 (STATA corporation, College Station, Texas, USA). All data presented are weighted using STATA survey procedures to account for the cluster sample design, with the exception of school characteristics. 
The survey sample was a three-stage stratified sample. At the first stage, $\mathrm{n}$ schools were selected out of the $\mathrm{N}$ number of secondary schools in Kampala, thus the selection probability of schools was computed as $p_{s}=n / N$.

At the second stage one stream per grade was randomly selected, and the selection probability at this stage was computed as $p_{c}=1 / M_{c}$, where $M_{c}$ is number of streams in grade $\mathrm{c}$ and $\mathrm{c}$ is $3,4,5$ and 6 .

At the third stage, systematic sampling was used to select students from the stream chosen at stage two. Assuming $k_{c}$ students were chosen from the total $K_{c}$ students in the chosen stream of grade c, and then the selection probability of students was computed as $p_{k}=k_{c} / K_{c}$.

The final sampling weight for each individual student was computed as the inverse of the overall selection probability i.e. Sampling weight $=1 /\left(p_{s} * p_{c} * p_{k}\right)$.

To estimate the prevalence of non-sexual adverse health behaviors, a univariate analysis was conducted using proportions. Pearson's chi-square tests were used to compare male and female characteristics. In bivariate and multivariate analysis, the main outcomes of interest were suicide ideation, school absenteeism, and engagement in physical violence. Age was dropped as an independent variable because majority of students were of average age. For bivariate analysis, we stratified by gender and computed odds ratios and their corresponding 95\% confidence intervals (CI). We used logistic regression stratified by gender for multivariable analysis. A full model was run for all independent variables irrespective of statistical significance at bivariate analysis. All variables that were statistically significant $(p<0.05)$ in the full model were considered as candidates for the reduced model. Possible collinearity was investigated for variables whose interpretability of their estimated coefficients and p-values changed at full model analysis when compared to that of bivariate analyses. As such, for any two variables found to be correlated, one was not considered for the reduced model taking into account the theoretical relevance of the variable to the outcome of interest.

\subsection{Ethical considerations}

The survey protocol was reviewed and approved by the Science and Ethics Committee of the Uganda Virus Research institute in Entebbe, the Uganda National Council of Science and Technology, and the U.S. Centers for Disease Control and Prevention (CDC-Atlanta, Georgia, USA). Investigators consulted with and obtained approvals from the selected schools and government authorities. For the selected schools, all parents of students in forms 3-6 were sent an information sheet about the survey and the possibility that their child may be selected for survey participation. Parents were informed that they could return the form (through their children) to indicate that they did not want their child to be enrolled, otherwise, survey staff may offer enrolment and assent their child. Students who were below 18 years of age were assented and those above 18 years were consented. Sampled students were enrolled if neither parent nor student indicated refusal. Student assent/consent was obtained electronically, using handheld computers. All participants were informed that they were free not to participate, free not to respond to any of the questions they felt uncomfortable with, and free to stop the interview at any time. Personal identifiers were not collected. After the interview, students were offered small gifts like pens, rulers and pencils valued at approximately one US dollar. No incentive was offered to participating schools.

\section{RESULTS AND ANALYSIS}

\subsection{Demographics}

Three thousand four-hundred thirty-one $(3,431)$ secondary school students attending form 3-6(grade 9-12), in 54 schools agreed to participate in the survey. The overall response rate for the survey was $68.2 \%$. The majority of respondents were female $(52.6 \%)$ and aged 18 years or below $(72.2 \%)$. The mean age for boys was 18.24 years (14-33) and for girls was 17.39years (13-27). Most were of normal weight (84.5\%, defined as a body mass index for age between 5th and 85th percentile) and had engaged in physical activity in the last seven days $(90.5 \%)$. One in seven students $(16.9 \%)$ tried to control weight by taking laxatives or vomiting; $27.2 \%$ ever consumed alcohol; $4.7 \%$ ever smoked tobacco products; $17.6 \%$ were bullied in the 30 days preceding the survey; $46.8 \%$ were seriously injured in the 12 months preceding the survey like broken bone, cut or stab wound, head or neck injury etc. and 5.4\% ever used illicit drugs like marijuana or banghi, khati etc. One in two students had been absent from school without permission in the 30 days preceding the survey. One in seven students (13.6\%, females: $17.2 \%$, males: $10.4 \%$ ) had considered committing suicide in the 12 months preceding the survey and $25.1 \%$ engaged in a physical violence. The details of the sociodemographic characteristics are shown in Table 1. 
Table 1. Socio-Demographic and Behavioral Characteristics of Secondary School Students $(\mathrm{N}=3,431)$, Kampala, Uganda, 2010

\begin{tabular}{|c|c|c|c|c|}
\hline Characteristic & $\begin{array}{l}\text { Male } \\
\mathrm{N}=1695\end{array}$ & $\begin{array}{l}\text { Female } \\
\mathrm{N}=1736\end{array}$ & $\begin{array}{l}\text { Total } \\
\mathrm{N}=3431\end{array}$ & p-value \\
\hline & $\mathrm{n}(\%)$ & $\mathrm{n}(\%)$ & $\mathrm{n}(\%)$ & \\
\hline Demographics & & & & $<0.001$ \\
\hline \multicolumn{5}{|l|}{ Age in years } \\
\hline$\leq 18$ & $1023(64.8)$ & $1355(80.3)$ & $2378(72.2)$ & \\
\hline$>18$ & $672(35.2)$ & $381(19.7)$ & $1053(27.8)$ & \\
\hline Weight status (BMI for age) ${ }^{\mathrm{a}}$ & & & & $<0.001$ \\
\hline Underweight $\left(<5^{\text {th }}\right.$ percentile $)$ & $220(13.1)$ & $42(2.4)$ & $262(8.0)$ & \\
\hline Normal $\left(5^{\text {th }}-85^{\text {th }}\right.$ percentile $)$ & $1446(84.9)$ & $1453(84.1)$ & $2899(84.5)$ & \\
\hline Overweight $\left(\leq 85^{\text {th }}-<95^{\text {th }}\right.$ percentile $)$ & $23(1.3)$ & $206(11.6)$ & $229(6.2)$ & \\
\hline Obese $\left(\geq 95^{\text {th }}\right.$ percentile $)$ & $5(0.7)$ & $35(1.9)$ & $40(1.3)$ & \\
\hline \multicolumn{5}{|l|}{ Independent Variables } \\
\hline Weight control by taking laxatives or vomiting & $310(16.1)$ & $333(17.8)$ & $643(16.9)$ & 0.330 \\
\hline Engaged in physical activity in last 7 days & $1557(91.2)$ & $1556(89.6)$ & $3113(90.5)$ & 0.290 \\
\hline Ever consumed alcohol & $559(33.0)$ & $377(20.9)$ & $936(27.2)$ & $<0.001$ \\
\hline Ever smoked tobacco & $130(7.0)$ & $39(2.2)$ & $169(4.7)$ & $<0.001$ \\
\hline Bullied in last 30 days & $309(18.4)$ & $287(17.0)$ & $596(17.6)$ & 0.544 \\
\hline Seriously injured in last 12 months & $857(47.6)$ & $831(46.0)$ & $1688(46.8)$ & 0.523 \\
\hline Ever consumed/used illicit drugs & $134(7.5)$ & $53(3.1)$ & $187(5.4)$ & $<0.001$ \\
\hline \multicolumn{5}{|l|}{ Dependent Variables } \\
\hline Absent from school without permission in last 30 days & $906(50.6)$ & $907(51.2)$ & $1813(50.9)$ & 0.806 \\
\hline Considered committing suicide in last 12 months & $218(10.4)$ & $306(17.2)$ & $524(13.6)$ & $<0.001$ \\
\hline Engaged in physical violence in last 12 months & $520(28.0)$ & $424(22.0)$ & $944(25.1)$ & 0.004 \\
\hline
\end{tabular}

\subsection{Bivariate analysis}

Table 2 shows the results of the bivariate analysis for potential factors associated with suicide ideation, school absenteeism, and engagement in physical violence. Weight control(odds ratio[OR]=2.99, 95\% CI [2.22-4.03]), ever having smoked ( $\mathrm{OR}=1.85$, 95\% CI [1.10-3.08]), serious injuries in the last 12 months $(\mathrm{OR}=1.90,95 \% \mathrm{CI}[1.42-2.54])$, ever having used illicit drugs(OR=2.15, 95\% CI[1.34-3.43]), school absenteeism(OR=1.67, 95\% CI [1.25-2.24]), engagement in physical violence $(\mathrm{OR}=2.07,95 \% \mathrm{CI}$ [1.56-2.74] ) and having been bullied in the 30 days preceding the survey(OR=1.64, 95\% CI [1.19-2.27] ) were positively associated with considering committing suicide. On stratification by gender, weight control and bullied in the last 30days preceding the survey were the predictors for suicide ideation in female students only $(\mathrm{OR}=2.45,95 \% \mathrm{CI}[1.65-3.63]$ and $\mathrm{OR}=2.04,95 \% \mathrm{CI}$ [1.33-3.33] respectively) whereas ever smoked was for the male students only $(\mathrm{OR}=2.28,95 \% \mathrm{CI}$ [1.21-4.30]) as shown in Table 2A.

School absenteeism was positively associated with ever consumed alcohol (OR=1.60, 95\% CI [1.272.02]), smoking tobacco ( $\mathrm{OR}=2.10,95 \% \mathrm{CI}$ [1.25- 3.55]), illicit drug use (OR=2.12, 95\% CI [1.26- 3.56]); having been bullied within 30 days $(\mathrm{OR}=1.73,95 \% \mathrm{CI}$ [1.33- 2.25]), serious injury in the last 12 months $(\mathrm{OR}=1.74,95 \% \mathrm{CI}$ [1.43-2.12], engagement in physical violence $(\mathrm{OR}=1.97,95 \% \mathrm{CI}$ [1.57-2.47] or considering committing suicide within the 12 months preceding the survey (OR=1.67-95\% CI [1.25-2.24]). On stratification by gender, ever smoked was a predictor for school absenteeism among the female students only $(\mathrm{OR}=4.50,95 \% \mathrm{CI}[1.80-11.20]$ as shown in Table $2 \mathrm{~B}$.

For engagement in physical violence, students who had ever smoked tobacco (OR=2.32; 95\% CI [1.49, 3.61]); engaged in a physical activity in the last 7 days(OR=2.52, 95\% CI [1.61-3.96]); had been absent from school $(\mathrm{OR}=1.97,95 \% \mathrm{CI}$ [1.57-2.47] $)$ and had suicide ideation(OR=2.07, 95\% CI [1.56-2.73]) were twice as likely to be engaged in physical violence than those who had never reported such behavior. Students who had ever used illicit drugs ( $\mathrm{OR}=3.21,95 \%$ CI $[2.04,5.04])$; had serious injury in the last 12 months $(\mathrm{OR}=3.66,95 \% \mathrm{CI}[2.88-4.66])$ and had been bullied in the preceding 30 days $(\mathrm{OR}=3.03$, $95 \%$ CI $[2.34,3.93])$ were three times more likely to have engaged in physical violence than those who did not report such behaviors. Students who had tried weight control were one and half times more likely to engage in physical violence than those who had never tried to control weight (OR=1.45, 95\% CI [1.12-1.88]). On stratification by gender, weight control was a predictor for engagement in physical violence among female students only $(\mathrm{OR}=1.60,95 \% \mathrm{CI}[1.11-2.28])$ whereas ever smoked was for male students only $(\mathrm{OR}=2.45,95 \% \mathrm{CI}[1.45-4.14])$ as shown in Table $2 \mathrm{C}$. 
Table 2. Bivariate Analysis of Health Risk Factors Potentially Associated with Suicide Ideation, Absenteeism and Engagement in Physical Violence among Secondary School Students in Kampala

\begin{tabular}{|c|c|c|c|c|c|c|}
\hline \multirow{2}{*}{ Factor } & \multicolumn{2}{|l|}{ Male } & \multicolumn{2}{|c|}{ Female } & \multicolumn{2}{|l|}{ Total } \\
\hline & $\mathrm{OR}(95 \% \mathrm{CI})$ & p-value & $\mathrm{OR}(95 \% \mathrm{CI})$ & p-value & $\mathrm{OR}(95 \% \mathrm{CI})$ & p-value \\
\hline Weight Control & $1.00(1.00-1.00)$ & 0.094 & $2.45(1.65-3.63)$ & $<0.001$ & $2.99(2.22-4.03)$ & $<0.001$ \\
\hline Ever Alcohol use & $1.45(0.94-2.23)$ & 0.095 & $1.30(0.88-1.94)$ & 0.191 & $1.24(0.93-1.67)$ & 0.148 \\
\hline Ever Smoked & $2.28(1.21-4.30)$ & 0.011 & $2.10(0.85-5.18)$ & 0.107 & $1.85(1.10-3.08)$ & 0.019 \\
\hline Bullied in the last 30 days & $1.28(0.79-2.06)$ & 0.31 & $2.04(1.33-3.13)$ & 0.001 & $1.64(1.19-2.27)$ & 0.003 \\
\hline School absenteeism & $1.76(1.13-2.72)$ & 0.012 & $1.62(1.09-2.39)$ & 0.016 & $1.67(1.25-2.24)$ & 0.001 \\
\hline Engagement in physical violence & $2.47(1.64-3.74)$ & $<0.001$ & $2.01(1.37-2.96)$ & $<0.001$ & $2.07(1.56-2.74)$ & $<0.001$ \\
\hline \multicolumn{7}{|c|}{ Table 2B. Factors Associated with School Absenteeism } \\
\hline Weight Control & $1.00(1.00-1.00)$ & 0.665 & $1.34(0.94-1.90)$ & 0.105 & $1.30(1.00-1.67)$ & 0.043 \\
\hline Physical Activity in last 7 days & $1.04(0.62-1.73)$ & 0.889 & $1.30(0.81-2.07)$ & 0.277 & $1.16(0.82-1.64)$ & 0.397 \\
\hline Ever used illicit drugs & $2.06(1.09-3.91)$ & 0.027 & $2.38(1.07-5.30)$ & 0.033 & $2.12(1.26-3.56)$ & 0.004 \\
\hline Suicide ideation & $1.76(1.13-2.72)$ & 0.012 & $1.62(1.09-2.39)$ & 0.016 & $1.67(1.25-2.24)$ & 0.001 \\
\hline Engagement in physical violence & $1.88(1.38-2.56)$ & $<0.001$ & $2.16(1.53-3.05)$ & $<0.001$ & $1.97(1.57-2.47)$ & $<0.001$ \\
\hline \multicolumn{7}{|c|}{ Table 2C. Factors Associated with Engagement in Physical Violence } \\
\hline Weight Control & $1.00(0.999-1.004)$ & 0.254 & $1.60(1.11-2.28)$ & 0.011 & $1.45(1.12-1.88)$ & 0.005 \\
\hline Physical Activity in last 7 days & $2.12(1.13-3.99)$ & 0.02 & $3.09(1.68-5.70)$ & $<0.001$ & $2.52(1.61-3.96)$ & $<0.001$ \\
\hline Ever Alcohol use & $1.24(0.91-1.70)$ & 0.18 & $1.08(0.76-1.54)$ & 0.662 & $1.23(0.97-1.56)$ & 0.084 \\
\hline Ever Smoked & $2.45(1.45-4.14)$ & 0.001 & $1.35(0.59-3.10)$ & 0.478 & $2.32(1.49-3.61)$ & $<0.001$ \\
\hline Bullied in the last 30 days & $3.05(2.11-4.43)$ & $<0.001$ & $3.07(2.13-4.42)$ & $<0.001$ & $3.03(2.34-3.93)$ & $<0.001$ \\
\hline Serious Injury in last 12 months & $3.61(2.60-5.02)$ & $<0.001$ & $3.83(2.68-5.40)$ & $<0.001$ & $3.66(2.88-4.66)$ & $<0.001$ \\
\hline Ever used illicit drugs & $3.16(1.80-5.53)$ & $<0.001$ & $2.78(1.35-5.72)$ & 0.006 & $3.21(2.04-5.04)$ & $<0.001$ \\
\hline School absenteeism & $1.88(1.38-2.56)$ & $<0.001$ & $2.16(1.53-3.08)$ & $<0.001$ & $1.97(1.57-2.47)$ & $<0.001$ \\
\hline
\end{tabular}

\subsection{Multivariable analysis}

In multivariate analysis, there was correlation between ever smoked and ever use of illicit drugs and between bullying and engagement in physical violence thus ever smoked and engagement in physical violence were dropped as independent variables in the reduced models. A lifetime history of illicit drug use $(\mathrm{aOR}=1.76 ; 95 \% \mathrm{CI}$ [1.10-2.82]), being absent from school (aOR=1.46, 95\% CI [1.09-1.97]) and having had a serious injury in the last 12 months $(\mathrm{aOR}=1.67$ [1.25-2.24]) were associated with suicide ideation as shown in Table 3A. Having been bullied in the preceding 30 days was a predictor of suicide ideation among the female students only after stratifying by gender.

Consistent with bivariate analysis, school absenteeism was positively associated with a lifetime history of alcohol use (aOR=1.55, 95\% CI [1.22-1.95]); having been bullied within the 30 days preceding the survey (aOR=1.52, 95\% CI [1.15-1.99]); having had a serious injury in the last 12 months (aOR=1.59, 95\% $\mathrm{CI}$ [1.29-1.95]) and suicide ideation within 12 months preceding the survey (aOR=1.45, 95\% CI [1.08-1.96]) as shown in Table 3B. Ever having consumed illicit drugs was no longer associated with school absenteeism.

All the factors, engagement in physical activity in the last 7 days $(\mathrm{aOR}=2.12,95 \%$ CI [1.35-3.35]; lifetime history of illicit drug use ( $\mathrm{aOR}=2.65,95 \% \mathrm{CI}$ [1.64-4.28]); having had a serious injury in the last 12 months $(\mathrm{aOR}=2.89,95 \% \mathrm{CI}$ [2.26-3.71]; having been absent from school $(\mathrm{aOR}=1.57,95 \%$ CI $[1.23-2.00]$; having considered committing suicide $(\mathrm{aOR}=1.58,95 \% \mathrm{CI}$ [1.17-2.14] and being bullied in the 30 days preceding the survey $(\mathrm{aOR}=2.38,95 \%$ CI $[1.80-3.14])$ were positively associated with engagement in physical violence as shown in Table $3 \mathrm{C}$. On stratification by gender, lifetime history of illicit drug use $(\mathrm{aOR}=3.06,95 \% \mathrm{CI}[1.74-5.38])$ and having considered committing suicide (aOR=2.00, 95\% CI [1.23-3.24]) were predictors of engagement in physical violence among the male students only. 
Table 3. Multivariable Logistic Regression Analysis of Health Risk Factors Potentially Associated with Suicide Ideation, Absenteeism

\begin{tabular}{|c|c|c|c|c|c|c|}
\hline \multirow[b]{2}{*}{ Factor } & \multicolumn{2}{|l|}{ Male } & \multicolumn{2}{|c|}{ Female } & \multicolumn{2}{|l|}{ Total } \\
\hline & $\mathrm{aOR}(95 \% \mathrm{CI})$ & p-value & $\mathrm{aOR}(95 \% \mathrm{CI})$ & p-value & $\mathrm{aOR}(95 \% \mathrm{CI})$ & p-value \\
\hline \multicolumn{7}{|c|}{ Table 3A. Factors Associated with Suicide Ideation } \\
\hline Bullied in the last 30 days & $1.07(0.63-1.80)$ & 0.800 & $1.73(1.12-2.67)$ & 0.014 & $1.39(0.99-1.94)$ & 0.056 \\
\hline Ever used illicit drugs & $1.98(1.05-3.75)$ & 0.036 & $2.04(1.01-4.10)$ & 0.047 & $1.76(1.10-2.82)$ & 0.018 \\
\hline School absenteeism & $1.52(0.99-2.34)$ & 0.058 & $1.42(0.95-2.12)$ & 0.084 & $1.46(1.09-1.97)$ & 0.012 \\
\hline \multicolumn{7}{|c|}{ Table 3B. Factors Associated with School Absenteeism } \\
\hline Serious Injury in last 12 months & $1.75(1.30-2.36)$ & $<0.001$ & $1.43(1.07-1.90)$ & 0.014 & $1.59(1.29-1.95)$ & $<0.001$ \\
\hline Ever used illicit drugs & $1.64(0.86-3.15)$ & 0.135 & $1.68(0.74-3.82)$ & 0.214 & $1.63(0.97-2.75)$ & 0.067 \\
\hline Suicide ideation & $1.48(0.96-2.30)$ & 0.079 & $1.41(0.94-2.10)$ & 0.95 & $1.45(1.08-1.96)$ & 0.014 \\
\hline \multicolumn{7}{|c|}{ Table 3C. Factors Associated with Engagement in Physical Violence } \\
\hline Physical Activity in last $7 \mathrm{~d}$ & $1.92(1.03-3.58)$ & 0.039 & $2.47(1.30-4.71)$ & 0.006 & $2.12(1.35-3.35)$ & 0.001 \\
\hline Suicide ideation & $2.00(1.23-3.24)$ & 0.005 & $1.46(0.98-2.16)$ & 0.062 & $1.58(1.17-2.14)$ & 0.003 \\
\hline
\end{tabular}

\section{DISCUSSION}

The survey provides estimates on the prevalence of both adverse and health promoting behaviors among secondary students. Students in Kampala are physically active and most have appropriate weight as demonstrated by the proportions of students who were either overweight $(6.2 \%)$ or obese $(1.3 \%)$. This could be explained by the fact that majority of students walk to school and their schools are engaged in competitive sports like athletics and football. This gives students a chance to exercise regularly. These are good indicators of positive school health behaviors given the fact that other studies have shown an increase in overweight and obesity among youth in low-income countries $[14,15]$. In this study, it was however observed that more female students $(13.5 \%)$ were overweight or obese compared to males $(2.0 \%)$ and $13.1 \%$ of the males were underweight compared to $2.4 \%$ for the female students.

In concurrence with other studies, adverse health behaviors like alcohol use (27.2\%), smoking (4.7\%), illicit drug use (5.4\%), exposure to physical violence (25.1\%), bullying (17.6\%), and suicidal ideation(13.6\%) were prevalent among students in Kampala [16, 18-20, 25, 28], and differ by gender [21, 22]. Adverse health behaviors were more prevalent among male students than female students, with the exception of suicidal ideation, which were almost twice as frequent in females compared to males.

Almost half of secondary students had a serious injury in the 12 months preceding the study. This is consistent with Blum et al. and Patton et al. in their analysis of the health of young people in developing countries, which identified unintentional injuries as a leading cause of death and disability [10, 11].

One in seven $(13.6 \%, 95 \%$ CI [12.00-15.20]) secondary students in Kampala self-reported suicidal ideation. This prevalence was less than the 18.8\% (95\% CI[16.00-21.60]) observed in the Global Schoolbased Student Health Survey(GSHS) conducted in Uganda in 2003 [28]. This might have been due to the difference in the area of coverage for the two surveys as the GSHS was a national survey whereas the study covered only Kampala. In multivariate analysis, suicidal ideation was positively associated with a lifetime history of exposure to illicit drugs, school absenteeism, and having had serious injury in the last 12 months. Lifetime history of exposure to illicit drugs as a risk factor to suicidal ideation has been described in other behavioral studies of Ugandan and American high school students [20, 24]. In contrast to this study, Borowsky et al in their study of risks and protectors of adolescent suicide attempts found skipping school was associated with attempting suicide among white adolescents and not among black adolescents thus bringing in a race/ethnicity factor[31]. This could be due to the difference in the study settings and the fact that race/ethnicity was not considered in this study. Literature on the association between serious injury and suicidal ideation is minimal. However, Andover et al in their review of empirical research on the factors uniquely associated with self-injury with or without suicidal intent among adolescents, show that suicidal ideation is strongly associated with suicide attempt and attempted suicide and non-suicidal self-injury (NSSI) commonly co-occur [32]. This could explain the survey findings of an association between serious injury and suicidal ideation. Although having been bullied was associated with suicidal ideation at bivariate analysis for gender, on multivariate analysis it was a risk factor for only female students. This was consistent with findings reported by Kim et al of female students who were victims of school bullying being three times at greater risk for suicidal ideation than were male students[33]. 
In this study, half of all students $(50.9 \%, 95 \%$ CI [48.5-53.4]) had been absent from school in the 30 days preceding the survey. This is higher than $34.8 \%$ (95\% CI [31.0-38.7]) that was reported in the GSHS study [28]. Factors positively associated with school absenteeism in this study were: lifetime history of alcohol use, having been bullied, serious injury in the last 12 months and suicidal ideation. There is limited available literature on the factors that are associated with school absenteeism although it is believed to be associated with disruptive behaviors among students when absentees return. Of note, more than one in five students were not present at school when selected for survey participation. Anecdotal information also suggests that non-payment of school fees (and subsequent non-admission or dismissal from school) is a challenge for many Kampala families.

Engagement in physical violence was exhibited by $25.1 \%$ (95\% CI [23.1-27.2]) of students. This was less than the $35.5 \%$ (95\% CI [32.1-39.0]) prevalence documented in the GSHS study among the Ugandan students, $43 \%$ in US high school students and 50.6\% among the school-enrolled adolescents in Namibia [18, 26, 28]. This could be explained by the fact that engagement in physical violence is punishable in Ugandan secondary schools thus this might have led to under reporting of engagement in physical violence by the students during the survey or over time punishments for engaging in physical violence have become a deterrent. Engagement in physical violence was associated with a lifetime history of illicit drug use, physical activity in the last 7 days, serious injury in the last 12 months, school absenteeism, suicide ideation and having been bullied. This was consistent with findings reported by Rudatsikira et al. of association between physical fights, illicit drug use, and bullying in their study among school-going adolescents in Namibia [18]. In addition, Dukarm et al. in their study of violent behavior among adolescents reported a significantly higher prevalence of violent behavior among adolescents who used illicit substances than among those who did not report any drug use [26]. Thullen et al in their study of suicide ideation and attempts among adolescents engaged in risk behavior reported perpetration of interpersonal violence and self-injury as some of the risk behaviors associated with suicide ideation[34]. There is limited available literature from other studies on the association between engagement in physical violence and physical activity, and school absenteeism.

The study had some limitations. First, all behavioral measures are based on self-report and as such are subject to reporting bias or recall bias. Also, survey participation was restricted to respondents in forms 3 to 6 (grade 9-12). Of note from Figure 1 is that $81 \%$ of the 678 students being replaced was due to absenteeism. But given that absenteeism is one of the outcomes of interest, it is possible that we may have had missing data that is not completely at random had we not made replacements. This may be a limitation for this paper since this was not taken into account during the modeling process. It may be of interest for future research to analyze the data with missing responses instead of making replacements. It would have been important to study the potential impact of absenteeism on estimates and representativeness. However, no data on absentee characteristics like age, sex, or form was available. Further, survey results cannot be generalized to all Ugandan students, as the survey was conducted only in Kampala and because of high absenteeism and lack of information on absentees, interpretation of results may be limited to the students sampled. The survey did not capture out-of-school youth of comparative age. The cross-sectional survey design precluded determination of causation of the factors associated with the dependent variables. Despite these limitations, the findings provide insights into health-related behaviors of secondary school students in Kampala.

The results of the survey can help inform program planners and policy makers responsible for school and youth health. The frequent reporting of school absenteeism, engagement in physical violence, serious injuries, bullying and suicidal tendencies is of concern. Parents, educators, secondary school leadership, and community leaders should consider ways to reduce such behaviors in schools and protect children from the adverse consequences.

\section{CONCLUSION}

The results of the survey can help inform program planners and policy makers responsible for school and youth health. The frequent reporting of school absenteeism, engagement in physical violence, serious injuries, bullying and suicidal tendencies is of concern. Parents, educators, secondary school leadership, and community leaders should consider ways to reduce such behaviors in schools and protect children from the adverse consequences.

\section{ACKNOWLEDGEMENTS}

The authors thank the Crane Survey staff, school principals, teachers, parents, and the secondary school students in Kampala for their time and efforts. The Crane Survey Staff included Wolfgang Hladik, 
George Lubwama, Rachel Kwezi, Mariam Namawejje, Gorreti Nakiwala, Justine Nanteza Nyende, and Stella Lunyolo.

All the authors contributed to the study design, study conduct, data analysis and interpretation, or manuscript writing. This research was supported by a Cooperative Grant (5U2GPS00097) to Makerere University School of Public Health, by U.S. Centers for Disease Control and Prevention under the President's Emergency Plan for AIDS Relief (PEPFAR). The findings and conclusions in this manuscript are those of the authors and do not necessarily represent the official position of the U.S. Centers for Disease Control and Prevention.

\section{REFERENCES}

[1] United Nations DoEaSA, Population Division, World Population Prospects: The 2010 Revision New York, 2011.

[2] Statistics UBo. The National Population and Housing Census 2014-Main Report. Kampala, Uganda: Uganda Bureau of Statistics. 1-108, 2016.

[3] Kelder SH, Perry CL, Klepp KI, Lytle LL, "Longitudinal tracking of adolescent smoking, physical activity, and food choice behaviors," Am J Public Health, 84(7): 1121-1126, 1994.

[4] McGinnis JM, Foege WH, "Actual causes of death in the United States," JAMA, 270(18): 2207-2212, 1993.

[5] Eaton DK, Kann L, Kinchen S, Shanklin S, Flint KH, Hawkins J, et al., "Youth risk behavior surveillance - United States, 2011," MMWR Surveill Summ, 61(4): 1-162, 2012.

[6] Wallace S. http://www.who.int/features/factfiles/adolescent_health/facts/en/index.htm. Published 2008. Accessed 20/04 2012.

[7] Guilbert JJ: The world health report 2002 - reducing risks, promoting healthy life. Educ Health (Abingdon), 16(2): 230, 2003.

[8] World Health Organisation. http://www.who.int/healthinfo/global_burden_disease/estimates/en/index 1.html. Published 2014. Accessed 20th April 2015.

[9] Noorani S. http://www.who.int/features/factfiles/adolescent_health/facts/en/index8.html. Published 2008. Accessed 20/04 2012.

[10] Blum RW, Nelson-Mmari K, "The health of young people in a global context," J Adolesc Health, 35(5): 402-418, 2004.

[11] Patton GC, Coffey C, Sawyer SM, Viner RM, Haller DM, Bose K, et al., "Global patterns of mortality in young people: a systematic analysis of population health data" Lancet, 374(9693): 881-892, 2009.

[12] Black C. http://www.who.int/features/factfiles/adolescent_health/facts/en/index4.html. Published 2008. Accessed 20/04 2012

[13] Giboux J. http://www.who.int/features/factfiles/adolescent_health/facts/en/index3.html. Published 2008. Accessed 20/04 2012.

[14] Kosti RI, Panagiotakos DB, "The epidemic of obesity in children and adolescents in the world" Cent Eur J Public Health, 14(4): 151-159, 2006.

[15] Reddy SP, Resnicow K, James S, Funani IN, Kambaran NS, Omardien RG, et al., Rapid increases in overweight and obesity among South African adolescents: comparison of data from the South African National Youth Risk Behaviour Survey in 2002 and 2008. Am J Public Health, 102(2): 262-268, 2012.

[16] Liang H, Flisher AJ, Lombard CJ, "Bullying, violence, and risk behavior in South African school students," Child Abuse Negl, 31(2): 161-171, 2007.

[17] Ogden CL, Carroll MD, Kit BK, Flegal KM, "Prevalence of Obesity and Trends in Body Mass Index among US Children and Adolescents," 1999-2010. JAMA, 307(5): 483-490, 2012.

[18] Rudatsikira E, Siziya S, Kazembe LN, Muula AS, "Prevalence and Associated Factors of Physical Fighting among School-Going Adolescents in Namibia," Ann Gen Psychiatry, 6: 18, 2007.

[19] Eaton DK, Kann L, Kinchen S, Shanklin S, Ross J, Hawkins J, et al., "Youth Risk Behavior Surveillance-United States, 2009," MMWR Surveill Summ, 59(5): 1-142, 2010.

[20] Rudatsikira E, Muula AS, Siziya S, Twa-Twa J, "Suicidal Ideation and Associated Factors among School-Going Adolescents in Rural Uganda," BMC Psychiatry, 7: 67, 2007.

[21] Ohene SA, Ireland M, Blum RW, "The Clustering of Risk Behaviors among Caribbean youth," Matern Child Health J, 9(1): 91-100, 2005.

[22] Siziya S, Ntata PR, Rudatsikira E, Makupe CM, Umar E, Muula AS, "Sex Differences in Prevalence Rates and Predictors of Cigarette Smoking among in-School Adolescents in Kilimanjaro, Tanzania," Tanzan Health Res Bull 9(3): 190-195, 2007.

[23] Toumbourou JW, Hemphill SA, McMorris BJ, Catalano RF, Patton GC, "Alcohol Use and Related Harms in School Students in the USA and Australia," Health Promot Int, 24(4): 373-382, 2009.

[24] Burge V, Felts M, Chenier T, Parrillo AV, "Drug Use, Sexual Activity, and Suicidal Behavior in U.S. High School Students," J Sch Health, 65(6): 222-227, 1995.

[25] Fleming LC, Jacobsen KH, "Bullying among Middle-School Students in Low and Middle Income Countries," Health Promot Int, 25(1): 73-84, 2010.

[26] Dukarm CP, Byrd RS, Auinger P, Weitzman M, "Illicit Substance Use, Gender, and The Risk of Violent Behavior among Adolescents," Arch Pediatr Adolesc Med, 150(8): 797-801, 1996.

[27] Farhat T, Iannotti RJ, Simons-Morton BG, "Overweight, Obesity, Youth, and Health-Risk Behaviors" Am J Prev Med, 38(3): 258-267, 2010. 
[28] Twa-Twa J, Oketcho S. "Global School Based Student Health Survey 2003- Uganda Country Report. Ministry of Health, Uganda," 1-43, 2003.

[29] Siziya S, Rudatsikira E, Muula AS, "Factors Associated With Current Cigarette Smoking among Adolescents in Ville du Sud, Cote d'Ivoire," Mali Med, 22(4): 40-46, 2007.

[30] Siziya S, Rudatsikira E, Muula AS, Ntata PR, "Predictors of cigarette smoking among adolescents in rural Zambia: results from a cross sectional study from Chongwe [corrected] district," Rural Remote Health, 7(3): 728, 2007.

[31] Borowsky IW, Ireland M, Resnick MD, "Adolescent Suicide Attempts: Risks and Protectors," Pediatrics 107(3): 485-493, 2001.

[32] Andover MS, Morris BW, Wren A, Bruzzese ME, "The Co-Occurrence of Non-Suicidal Self-Injury and Attempted Suicide among Adolescents: Distinguishing Risk Factors and Psychosocial Correlates," Child and Adolescent Psychiatry and Mental Health, 6(11): 1-7, 2012.

[33] Kim YS, Koh Y-J, Leventhal B, "School Bullying and Suicidal Risk in Korean Middle School Students," Pediatrics, 115(2): 357-363, 2005.

[34] Thullen MJ, Taliaferro LA, Muehlenkamp JJ, "Suicide Ideation and Attempts Among Adolescents Engaged in Risk Behaviors: A Latent Class Analysis," Journal of Research on Adolescence, n/a-n/a, 2015. 